\title{
ФИЛОЛОГИЧЕСКОЕ ОБРАЗОВАНИЕ
}

УДК 37:001.12/18

DOI: 10.23951/1609-624X-2018-1-40-44

\section{МЕТОДИЧЕСКИЙ АСПЕКТ РАБОТЫ СО СЛОВАРЯМИ В НАЧАЛЬНОЙ ШКОЛЕ}

\author{
Н. В. Достовалова ${ }^{1}$, М. В. Курышева ${ }^{2}$ \\ ${ }^{1}$ Муниципальное автономное общеобразовательное учреждение гимназия № 18, Томск \\ ${ }^{2}$ Томский государственный педагогический университет, Томск
}

\begin{abstract}
Описана методика работы с лингвистическими словарями разных типов в начальной школе, указаны факторы, негативно влияющие на формирование навыков работы со словарями, выделены этапы работы со словарями, условия эффективности такой работы, комплекс учебных действий работы со словарями. Определены требования к современному словарю для младших школьников. Особое внимание уделяется методике работы с толковым, орфографическим и орфоэпическим словарями.
\end{abstract}

Ключевые слова: начальная школа, метапредметные результаты, общеучебные умения, лингвистические словари, методика работы со словарем, особенности словарей разного типа, словарь для младшего школьника.

Словарный запас, которым владеет ребенок, был всегда предметом внимания ученых - исследователей детской речи, среди которых можно выделить Л. С. Выготского, М. Р. Львова, А. Н. Гвоздева, С. Н. Цейтлин и др.

Как отмечает М. Р. Львов, ребенок-первоклассник употребляет в своей речи от 2,5-3 тысяч слов до 7-8 тысяч, включая активную и пассивную лексику [1, с. 295]. Причем пассивный лексический запас больше, чем активный. Перевод пассивной лексики в активную является важной задачей обучения в школе, так как только при достаточном количестве слов-операторов мыслительных процессов возможно в полной мере развитие вербально-логического мышления. Одним из решений этой проблемы, безусловно, является обогащение лексикона младшего школьника через работу со словарями.

В письме Министерства образования и науки Российской Федерации от 6 мая 2013 года № 08535 «О формировании культуры работы со словарями в системе общего образования Российской Федерации» сказано, что «формирование у школьников потребности в обращении к словарям и навыков работы с ними, способности извлекать из словарей информацию, необходимую для решения учебных задач по разным предметным областям, во внеурочной и внеклассной деятельности должно стать одной из норм образования», именно «в начальной школе закладываются потребности обращения к словарям и общеучебные умения пользования ими» [2]. Умение пользоваться словарями относится, безусловно, к универсальным учебным действиям, под которыми понимается «комплекс образовательных способов поведения учащихся, состоящих из планирования траектории достижения учебных результатов, анализа их параметров, выбора соответствующих учебным целям путей достижения, контролирования приобретенного опыта и сравнения его с ожидаемым результатом..., а также коррекции и конструирования нового знания» [3, с. 30].

Сегодня трудно представить обучение русскому языку без обращения к лексикографическим источникам. Поэтому учитель начальных классов должен знать методику работы со словарями разных типов, уметь формировать навыки работы со словарями у школьников. Ведь, как отмечает М. С. Соловейчик, «если на более ранних этапах обучения ребенку не привита потребность обращаться к словарям, если у него не сформировалось умение ориентироваться в средствах помощи и быстро находить нужную информацию, то едва ли он станет полноценным пользователем всего существующего богатства словарей. Едва ли возникший пробел в дальнейшем удастся полноценно восполнить» $[4$, с. 30$]$.

Проблеме обучения младших школьников пользованию лингвистическими словарями всегда уделялось большое внимание и с разных позиций. Например, Н. М. Лаврова, И. В. Осипова, Н. П. Пикалова рассматривали эту проблему в аспекте формирования общеучебных умений, М. Л. Кускова, С. В. Плотникова, В. Д. Черняк - в аспекте лексикографической компетенции, В. В. Репкин, А. А. Бондаренко и др. - в 
аспекте определения принципов составления учебных словарей разных типов. Однако ни для кого не секрет, что словари, несмотря на свою значимость, не заняли своего места в обучении и развитии младшего школьника. Почему же у многих учеников начальных классов не сформирован навык пользования словарями? Авторы выделяют три негативных фактора: 1) редко учителями начальных классов создаются условия по возникновению потребности обращения к словарю; 2) учителя начальных классов, особенно молодые специалисты, не умеют грамотно организовать работу с ними на уроках, так как сами не знают особенностей каждого типа словарей; 3) в современной методике технологии работы со словарями практически не рассматриваются.

Начиная работу с лингвистическим словарем, учитель начальных классов должен четко представлять цель и результаты этой работы. Главной целью обучения младших школьников пользоваться словарями является способность и готовность учащихся обращаться к лингвистическим словарям разных типов для решения различных учебно-познавательных задач. Проявлением этой способности можно считать отношение к словарю и к содержащейся в нем информации как к некой ценности, наличие знаний о словарях разного типа и о способах работы с каждым из них, сформированность целого ряда умений по поиску, извлечению и использованию полученной из словаря информации, опыт использования словарей для решения различных задач. Эти умения универсальны и являются основой любой учебной деятельности $[5,6]$.

За последние десятилетия издательствами нашей страны выпущено огромное количество словарей. Но далеко не каждый из них является словарем для младшего школьника. Актуальность этой проблемы еще в конце прошлого столетия подчеркивала в своих работах А. А. Бондаренко: «...словарь для ребенка должен быть „по росту“, „,о размеру“ - по возрасту» [7, с. 27]. На наш взгляд, словари для начальной школы должны отвечать следующим требованиям:

1. Объем слов не должен превышать в целом 5 тысяч слов (толковый - от 3 до 5 тысяч слов, орфографический - 1-2 тысячи слов, орфоэпический - около 1 тысячи слов).

2. В состав словника должны быть включены слова, активно используемые младшими школьниками в речи.

3. Словарь должен быть актуален для данного УМК: содержание словарей должно соответствовать упражнениям, заданиям, художественным и научно-популярным текстам используемых УМК.

4. Словари должны быть разных типов, что обуславливает освоение учащимися различных алгоритмов работы с ними.
Тексты словарных статей следует отнести к информационным, исследования же последнего времени показывают, что младшие школьники испытывают затруднения при восприятии и выделении смысловых компонентов таких текстов; этому нужно специально учить [8]. Для того чтобы работа со словарями была эффективной, необходимо соблюдать несколько условий:

- формирование навыка работы со словарями должно быть постепенным;

- использование словарей на уроках в начальной школе должно быть систематическим.

Постепенное формирование навыков работы со словарями включает в себя поэтапное знакомство с ними (с его устройством, принципом расположения слов, языковыми пометами). Систематическое использование предполагает работу со словарями в течение всего периода в начальной школе на 3-4 уроках в неделю для выполнения различных видов работ и в разной форме (коллективной или индивидуальной, творческой или репродуктивной, устной или письменной). Начинать работу можно с момента освоения навыков чтения. При организации работы со словарями учитель начальных классов должен учитывать возрастные особенности своих учащихся и знать предметный материал, который изучается в данном классе.

В работе со словарями выделяют три этапа: подготовительный, этап первичного знакомства, основной.

На подготовительном этапе учителю необходимо сформировать у школьников элементарные умения обращения со словарем, подготовить их к выполнению соответствующих заданий. На данном этапе основная работа должна быть направлена на запоминание алфавита.

На этапе первичного знакомства учащиеся под руководством учителя знакомятся со словарем: автор, название, принцип расположения слов, языковые пометы. На основном этапе дети продолжают знакомство со структурой и содержанием словаря. Именно на этом этапе младшему школьнику пригодится знание алфавита. Начать работу можно со знакомства с орфографическим словарем, особенно актуальным в период обучения грамоте. Основной задачей работы является формирование навыка нахождения слова по первой, а затем по второй и по третьей буквам. Можно использовать такие задания, как найти слово и объяснить его место в словаре, объяснить, почему слово вокзал расположено выше, чем слово восток и под. При этом важно обратить внимание детей на то, что заглавное слово в словарной статье стоит в начальной форме и бесполезно искать словоформы шел, хочешь, соберу, земель, выйдя и под. Также следует обратить внимание на орфоэпическую информацию - по- 
становку ударения. Однако ударение в формах слова (на́чал - начался́, подари́л - пода́рищь и под.) можно выяснить только в орфоэпическом словаре. Большую роль здесь играют занимательные задания и упражнения.

И. В. Гуркова рекомендует всегда называть страницу словаря детям, чтобы не тратить время на поиск нужного слова [9]. Методисты УМК «Перспективная начальная школа» считают, что, наоборот, детям надо дать возможность полистать страницы словаря. Тот ребенок, который находит слово первым, называет нужную страницу. Основной этап можно закончить небольшой проверочной работой по поиску слова в словаре.

Особенности работы со словарем определяются его типом. Основными для начальной школы предлагаем считать толковый, орфографический, орфоэпический словари. Причем толковый словарь должен стать настольной книгой ребенка. М. Р. Львовым были сформулированы общие методические принципы работы с толковым словарем [1]. По его мнению, каждое из новых слов проходит четыре этапа работы с ним: 1) обнаружение нового слова; 2) выяснение толкования значения слова; 3) выполнение упражнений с новым словом; 4) активизация словаря, то есть перенесение нового слова из пассивного словаря в активный. Автор выделяет приемы объяснения значений слов:

1. Самостоятельные, то есть без помощи учителя, например, по картинке, по сноске на странице учебника, по словарикам в конце учебника, словарям, по догадке.

2. С помощью учителя (подбор синонимом, антонимов, объяснение учителем, через словообразование, через иностранный язык).

При этом, по мнению М. Р. Львова, слово считается активизированным, если ребенок использовал его хотя бы один раз в свободной, неподсказанной устной или письменной речи.

На наш взгляд, важно работать с толковым словарем не только на уроках филологического цикла, но и на уроках математики, окружающего мира, технологии, изобразительного искусства. Кроме обозначенных типов словарей в 3-4 классах целесообразно познакомить школьников со словарями си- нонимов, антонимов, этимологическим, фразеологическим, словообразовательным.

Таким образом, при работе с лингвистическими словарями разных типов младший школьник должен знать:

- какие вопросы он может решить с помощью словаря: как пишется слово, как оно произносится, каково его значение, с какими словами связано, в какие устойчивые выражения входит;

- какие лингвистические словари помогают ответить на возникшие вопросы - толковый, орфографический, орфоэпический и др.;

- как устроен словарь, из каких частей состоит, каково назначение этих частей;

- как устроена словарная статья лингвистических словарей разных типов.

Эти знания служат основой для сознательного освоения школьниками целого комплекса действий со словарями:

- осознание лингвистического затруднения и формулирование лексикографического запроса;

- определение типа словаря (в пределах изученных типов) и выбор словаря в соответствии с запроcom;

- ориентировка в словаре - выделение в нем пояснительной и словарной части, выделение в пояснительной части элементов, облегчающих поиск информации (цель словаря, описание словарной статьи, список сокращений), поиск в словаре нужной словарной статьи;

- ориентировка в структуре словарной статьи выделение заголовка статьи, других частей (в соответствии с типом словаря), поиск в статье необходимой информации, чтение и понимание словарных помет, использование ссылок [10].

При этом, как указывает С. В. Плотникова [10], в учебной работе может быть развернуто только одно из действий или даже отдельные его операции, но представлены они должны быть как элементы осмысленной деятельности, для чего в образовательном процессе создаются ситуации, мотивирующие младшего школьника обращаться к словарям для решения таких задач, как определение лексического значения слова, проверка правописания и произношения слова.

\section{Список литературы}

1. Львов М. Р., Горецкий В. Г., Сосновская О. В. Методика преподавания русского языка в начальных классах: учебное пособие для студ. высш. пед. учеб. заведений. М.: Академия, 2007. 464 с.

2. Письмо Минобрнауки России от 06.05.2013 N 08-535 «О формировании культуры работы со словарями в системе общего образования Российской Федерации (вместе с Методическими рекомендациями по формированию культуры работы со словарями школьников и педагогов общеобразовательных учреждений в целях реализации положений ФГОС)». URL: http://www.consultant.ru (дата обращения: 25.07.2017).

3. Леушина И. С., Темербекова А. А. Анализ основных подходов к определению понятия «универсальные учебные действия» в условиях Федерального государственного образовательного стандарта // Вестн. Томского гос. пед. ун-та (TSPU Bulletin). 2017. № 1 (178). С. 30.

4. Соловейчик М. С., Харченко О. О. Современные подходы к обучению орфографии в начальных классах // Цикл лекций на заочных курсах повышения квалификации учителей в педагогическом университете «Первое сентября»: газета «Начальная школа». 2006. № 17-24. С. 1-76. 
5. Поздеева С. И. Особенности формирования коммуникативных универсальных учебных действий в школе совместной деятельности // Вестн. Томского гос. пед. ун-та (TSPU Bulletin). 2016. № 12 (177). С. 24-26.

6. Медникова О. Н. Технология развития критического мышления через чтение и письмо как средство развития рефлексивной деятельности учащихся // Вестн. Томского гос. пед. ун-та (TSPU Bulletin). 2015. № 6 (159). С. 17-19.

7. Бондаренко А. А. Словари для малышей // Начальная школа. 1993. № 10. С. 28-32.

8. Поздеева С. И. К проблеме формирования у младших школьников умений работать с информационными текстами // Вестн. Томского гос. пед. ун-та (TSPU Bulletin). 2016. № 5 (170). С. 28-30.

9. Гуркова И. В. Методика работы со словарями как фактор формирования профессиональных компетенций учителя начальных классов // Сибирский педагогический журнал. 2014. № 5. С. 38-43.

10. Плотникова С. В. Формирование информационной компетентности младших школьников на материале словарей русского языка // Педагогическое образование в России. 2014. № 3. С. 128-133.

Достовалова Надежда Владимировна, учитель начальных классов, Муниципальное автономное общеобразовательное учреждение гимназия № 18 (ул. Киевская, 111, Томск, Россия, 634012). E-mail: nadya506@yandex.ru

Курышева Маргарита Викторовна, кандидат филологических наук, доцент, Томский государственный педагогический университет (ул. Киевская, 60, Томск, Россия, 634061). E-mail: marcur@yandex.ru

Материал поступил в редакциию 24.10.2017.

DOI: 10.23951/1609-624X-2018-1-40-44

\title{
METHODOLOGICAL ASPECTS OF WORK WITH DICTIONARIES IN PRIMARY SCHOOL
}

\author{
N. V. Dostovalova ${ }^{1}$, M. V. Kurysheva ${ }^{2}$
}

${ }^{1}$ MAEI gymnasium 18, Tomsk, Russian Federation

${ }^{2}$ Tomsk State Pedagogical University, Tomsk, Russian Federation

The article describes the method of working with the linguistic dictionaries of different types in elementary school. The importance of this topic is conditioned by the need to develop verbal-logic thinking of junior schoolchild, which is impossible without a sufficient amount of words - operators of cognitive processes. For this reason, an important place in the new standards for primary education is given to training to work with dictionaries. The authors point to the factors affecting the formation of skills of work with dictionaries, namely: teachers do not form the conditions under which a child should use a dictionary; teachers do not have sufficient preparation for such work; There are no reasonable technologies for working with dictionaries. Meanwhile, the ability to use reference books is a universal educational action, every student should have this ability. The ratio of the dictionary and the information contained in it to the value, knowledge of dictionaries of various types, and how each of them can be considered is a manifestation of this ability. In this regard the authors identify phases of work with dictionaries in primary school, the conditions of effectiveness of this work, describe the set of learning actions with dictionaries. Requirements for modern dictionary for a junior schoolchild include, in particular, quantity limitation, the actual structure of the Glossary, a close connection with the educational-methodical complex used in this class. Special attention is paid to the methods of work with monolingual, spelling and orthoepic dictionaries, which are basic for junior schoolchild.

Key words: primary school, metasubject results, learning skills, linguistic dictionaries, methods of work with the dictionary, features of dictionaries of different types, dictionaries for primary school children.

\section{References}

1. L'vov M. R., Goretskiy V. G., Sosnovskaya O. V. Metodika prepodavaniya russkogo yazyka v nachal'nykh klassakh: uchebnoye posobiye dlya studentov vysshykh pedagogicheskikh uchebnykh zavedeniy [Methods of the Russian language teaching in primary school: textbook for students of higher pedagogical educational institutions]. Moscow, Akademiya Publ., 2007. 464 p. (in Russian).

2. Pis'mo Minobrnauki Rossii ot 06.05.2013 N 08-535 «O formirovanii kul'tury raboty so slovaryami v sisteme obshchego obrazovaniya Rossiyskoy Federatsii (vmeste s Metodicheskimi rekomendatsiyami po formirovaniyu kul'tury raboty so slovaryami shkol'nikov $i$ pedagogov obshcheobrazovatel'nykh uchrezhdeniy v tselyakh realizatsii polozheniy FGOS)» [Letter of the Ministry of Education and Science of Russia from 05.05.2013 N 08-535 "About the formation of culture of work with dictionaries in the system of general education of Russian Federation" (together with the Methodological Recommendations on the formation of the culture of work with dictionaries of schoolchildren and teachers of general educational institutions in order to implement the regulations of GSES)] (in Russian). URL: http://www.consultant.ru (accessed 25 Jule 2017 ).

3. Leushina I. S., Temerbekova A. A. Analiz osnovnykh podkhodov k opredeleniyu ponyatiya «universal'nye uchebnye deystviya» v usloviyakh Federal'nogo gosudarstvennogo obrazovatel'nogo standarta [Analysis of the main approaches to definition of the concept «universal educational actions»]. Vestnik Tomskogo gosudarstvennogo pedagogicheskogo universiteta - TSPU Bulletin, 2017, no. 1 (72), p. 30 (in Russian). 
4. Soloveychik M. S., Kharchenko O. O. Sovremennye podkhody k obucheniyu orfografii v nachal'nykh klassakh [Modern approaches to spelling training in primary school]. Tsikl lektsiy na zaochnykh kursakh povysheniya kvalifikatsii uchiteley v pedagogicheskom universitete «Pervoye sentyabrya»: gazeta "Nachal'naya shkola» - A series of lectures on extramural courses for teachers in the Pedagogical University "The First of September»: the newspaper «Primary school», 2006, no. 17-24, p. 1-76 (in Russian).

5. Pozdeeva S. I. Osobennosti formirovaniya kommunikativnykh universal'nykh uchebnykh deystviy v shkole sovmestnoy deyatel'nosti [Features of universal communicative action formation at school of joint activity]. Vestnik Tomskogo gosudarstvennogo pedagogicheskogo universiteta TSPU Bulletin, 2016, no. 12 (177), pp. 24-26 (in Russian).

6. Mednikova O. N. Tekhnologiya razvitiya kriticheskogo myshleniya cherez chteniye i pis'mo kak sredstvo razvitiya refleksivnoy deyatel'nosti uchashchikhsya [Technology of the development of critical thinking through reading and writing as means of developing students' reflective activiti]. Vestnik Tomskogo gosudarstvennogo pedagogicheskogo universiteta - TSPU Bulletin, 2015, no. 6 (159), pp. 17-19 (in Russian).

7. Bondarenko A. A. Slovari dlya malyshey [Dictionaries for children]. Nachal'naya shkola, 1993, no. 10, pp. $28-32$ (in Russian).

8. Pozdeeva S. I. K probleme formirovaniya u mladshikh shkol'nikov umeniy rabotat' $s$ informatsionnymi tekstami [On the problem of formation yonger schoolchildren's abilities to work with informational text]. Vestnik Tomskogo gosudarstvennogo pedagogicheskogo universiteta - TSPU Bulletin, 2016, no. 5 (170), pp. 28-30 (in Russian).

9. Gurkova I. V. Metodika raboty so slovaryami kak faktor formirovaniya professional'nykh kompetentsiy uchitelya nachal'nykh klassov [Methods of working with dictionaries as factor of formation professional competence of primary school teacher]. Sibirskiy pedagogicheskiy zhurnal - Siberian Pedagogical Journal, 2014, no. 5, pp. 38-43 (in Russian).

10. Plotnikova S. V. Formirovaniye informatsionnoy kompetentnosti mladshikh shkol'nikov na materiale slovarey russkogo yazyka [The formation of junior schoolchildren information competence on the material of the Russian language dictionaries]. Pedagogicheskoye obrazovaniye $v$ Rossii Pedagogical Education in Russia, 2014, no. 3, pp.128-133 (in Russian).

Dostovalova N. V., MAEI gymnasium 18 (ul. Kievskaya, 111, Tomsk, Russian Federation, 634012). E-mail nadya506@yandex.ru

Kurysheva M. V., Tomsk State Pedagogical University (ul. Kievskaya, 60, Tomsk, Russian Federation, 634061). E-mail: marcur@ yandex.ru 